\title{
Kinetic parameters for thermal inactivation of soluble peroxidase from needles of Serbian spruce Picea omorika (Pančić) Purkynĕ
}

\author{
Danijela Laketa ${ }^{1}$, Jelena Bogdanović ${ }^{2}$, Aleksandar Kalauzi ${ }^{2}$ and Ksenija Radotić ${ }^{2}$ \\ ${ }^{1}$ Faculty of Biology, University of Belgrade, Studentski trg. 3-5, 11000 Beograd, Serbia \\ ${ }^{2}$ Institute for Multidisciplinary Research, Kneza Višeslava 1, 11000 Beograd, Serbia
}

\begin{abstract}
Thermal inactivation of peroxidase (POD) in an extract of Picea omorika (Pančić) Purkynĕ needles initiated by heat treatment was studied. This is the first study of this kind on a conifer species. Non-linear regression analysis was applied on the inactivation rate data, combining Mitscherlich and Arrhenius equations, treating time and temperature simultaneously as explaining variables. We determined the inactivation rate constant $k$, the Arrhenius energy of inactivation $E$ and the remaining activity $C_{\min }$ for the crude extract and for separated acidic and basic enzyme fractions, as well as for individual isoenzymes separated electrophoretically. A comparison of inactivation parameters for acidic and basic fractions shows that the thermal inactivation rate of the basic fraction is higher. The obtained value of inactivation energy for crude extract was between the values for acidic and basic isoenzyme fractions. One of the three analysed individual isoenzymes was characterised by a lower inactivation rate constant and higher inactivation energy. Another isoenzyme showed considerably higher level of remaining activity compared to the others, which identified it as the most resistant to high temperatures. The acquired values of Arrhenius energy of inactivation for POD in crude extract were intermediate, considering a range of POD values for various other plant species.
\end{abstract}

Key words: Picea omorika (Pančić) Purkyně - Peroxidase isoenzymes - Thermal inactivation - Inactivation kinetics

\section{Introduction}

Within the superfamily of plant, fungal and bacterial peroxidases (PODs; E.C. 1.11.1.7.), three related structural classes have been defined. Class III PODs contains all the secretory plant PODs which show distinctive features from other plant PODs. They are of glycoprotein nature and are located in vacuoles and cell walls. They show a broad range in their substrate requirements with noticeable substrate specificity for phenols (Ros Barceló 2000). PODs of class III have been intensively studied because of their multifunctionality and an important role in plant organisms, especially regarding their response to various kinds of stress (Castillo 1986; Ros Barceló 2000; Kawano 2003; Takahama 2004). PODs of class III are known for their high thermal stability compared to other POD classes, most evidently referred to the oligosaccharide component of the enzyme (Aiman and

Correspondence to: Ksenija Radotić, Institute for Multidisciplinary Research, Kneza Višeslava 1, 11000 Beograd, Serbia

E-mail: xenia@ibiss.bg.ac.yu
Qayyum 2007). Van Huystee et al. (2004) have shown that POD deglycosylation increases susceptibility to thermal inactivation. Reports on thermal resistance and temperature inactivation are very frequent for agricultural plant species since POD may be used as an indicator enzyme in the process of fruit and vegetable conservation (Rodrigo et al. 1996; Hendrickx et al. 1998; Anthon and Barrett 2002; Anthon et al. 2002; Morales-Blancas et al. 2002; Schweiggert et al. 2006; Vasquez-Caicedo et al. 2007). No data is currently available in literature on the thermal stability of PODs in conifers.

Serbian spruce (Picea omorika (Pančić) Purkynĕ) is a Balkan endemic coniferous species and a Tertiary relict of the European flora. Before the last glacial period P. omorika occupied a large area in Europe. After the Ice Age the habitat of this species is rather narrow (approx. $10,000 \mathrm{~km}^{2}$ ), occupying exclusively the middle and upper courses around the river Drina - the present territory of Serbia and Bosnia (Jovanović 1970). On the other hand, this species is more tolerant to the air pollution and drought compared to the other conifers (Gilman and Watson 1994; Král 2002). All these facts make this species very interesting for investiga- 
tions. P. omorika grows in a large edaphic and altitudinal range $(300-1600 \mathrm{~m})$. It is a shade-avoiding plant restricted to open habitats, forest clearings and cliffs (Čolić 1957, 1966; Tucić and Stojković 2001). In such habitats, P. omorika is exposed to high irradiation, UV radiation and large daily and seasonal fluctuations of temperature (Bazzaz 1996). For survival in such habitats, the antioxidative system may have a vital function, being involved in stress protection. As PODs represent a considerable segment of the protective system, studies of the influence of various stressors on this class of enzymes may be of great interest. Class III PODs in many plants are known for their variable number of isoenzymes differing in their properties (Van Huystee 1987). As temperature fluctuations are considerable in natural habitats of P. omorika, an analysis of the relation between temperature and POD activity may identify individual isoenzymes that are most resistant and therefore might participate in protection from temperature stress. There have been only a few studies of the antioxidative system of this species (Bogdanović et al. $2005,2006,2007)$, but none of them have analyzed effect of temperature on POD.

We studied thermal inactivation of POD in an extract of P. omorika needles initiated by heat treatment. Inactivation of the enzyme was studied in crude extract and in the acidic and basic fractions of isoenzymes separated by preparative electrophoresis, as well as the inactivation of individual isoenzymes separated electrophoretically. To describe thermal inactivation of POD, we chose three characteristic parameters: the rate of inactivation, expressed as a rate constant $(k)$, the energy of inactivation $(E)$ and the remaining activity $\left(C_{\text {min }}\right)$. In the crude extract, where multiple isoenzymes are present, overall inactivation rate at specified temperature is a resultant of individual isoenzyme inactivation rates.

This is the first study of influence of high temperatures on POD in a conifer species. Besides, obtained results may be useful in investigations of the natural adaptation of P. omorika species. More generally, such experiments could be of assistance in expanding the living area range of P. omorika, which is, as mentioned above, a species more tolerant to drought and pollution than the other conifers, that are continuously increasing in the environment.

\section{Materials and Methods}

\section{Plant material}

The needles were obtained from 15 -year-old $P$. omorika trees grown in a generative seed orchard at Godovik $\left(43^{\circ} 51^{\prime} \mathrm{N}\right.$, $20^{\circ} 02^{\prime} \mathrm{E}, 400 \mathrm{~m}$ a.s.l.), Serbia. The samples (2-year-old needles) were collected from four different trees and immediately stored in liquid nitrogen.

\section{Enzyme extraction and experimental setup}

All reagents and substances used in the experiments were of analytical grade and obtained from Sigma (Germany).

Frozen needles were powdered in liquid nitrogen in a mortar. Further extraction steps were carried at $+4^{\circ} \mathrm{C}$. The powder was resuspended in an extraction buffer $(0.1$ $\mathrm{mol} / \mathrm{l}$ TRIS-HCl, pH 7.6, containing $1 \mathrm{mmol} / \mathrm{l}$ dithiotreitol, $1 \mathrm{mmol} / \mathrm{l}$ EDTA (ethylenediaminotetraacetic acid) and 2\% PVP (polyvinylpyrrolidone), in $1: 5(\mathrm{w} / \mathrm{v})$ ratio). The homogenates were stirred on ice for $30 \mathrm{~min}$ and centrifuged at $12,000 \times g$ for $10 \mathrm{~min}$. The supernatant was desalted on Sephadex G-25 (NAP-5 column; Amersham Biosciences, Germany) and used for experiments.

At first, the activity and also isoenzyme profile of crude extract was determined for control sample (unheated) and samples that were subjected to the heating procedure.

In the second phase of the experiment, acidic and basic enzyme fraction were separated in unheated crude extract, using preparative electrophoresis. Both fractions were subjected to the heating procedure and subsequent activity measurements.

In the third part of the experiment, quantitative activity analysis of individual POD isoenzymes was performed on zymograms that contained control (unheated) and heated samples.

Finally, we used a mathematical analysis of the data obtained in all described experimental steps, to characterize the process of thermal inactivation of POD in the extract of P. omorika needles.

\section{Determination of enzyme activity}

POD activity was determined spectrophotometrically, using a Shimadzu UV-2501 PC spectrophotometer, at $22^{\circ} \mathrm{C}$ in a total volume of $3 \mathrm{ml}$. POD activity was determined with guaiacol as a substrate (Chance and Maehly 1955). The assay mixture contained $50 \mathrm{mmol} / \mathrm{l}$ acetate buffer ( $\mathrm{pH} 4.5), 100 \mu \mathrm{l}$ enzyme extract, $92 \mathrm{mmol} / \mathrm{l}$ guaiacol and $18 \mathrm{mmol} / \mathrm{H} \mathrm{H}_{2} \mathrm{O}_{2}$. After adding the substrate, its turnover was continually monitored during $180 \mathrm{~s}$ at $470 \mathrm{~nm}$. The reaction rate was usually expressed as $\mathrm{dA} \cdot \mathrm{min}^{-1}$. The enzyme specific activity was calculated from the extinction coefficient for guaiacol of $25.5 \mathrm{ml}(\mathrm{molcm})^{-1}$ and expressed in international units per gram of fresh weight of the sample.

\section{Thermal inactivation of enzyme extract}

Aliquots of enzyme extract $(100 \mu \mathrm{l})$ were transferred to glass tubes ( $5 \mathrm{~mm}$ I.D. $\times 6 \mathrm{~mm}$ O.D. $\times 70 \mathrm{~mm}$ length) with a syringe, covered with para-film and held on ice until heating. Samples were heated in a thermostated water bath (model VBS, Vacuum Technology) to different temperatures 


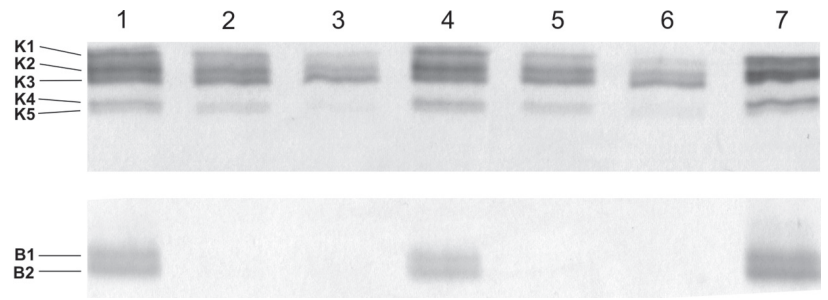

Figure 1. Isoenzyme profile of soluble POD in crude extract of P. omorika needles. Lanes 1-6 contain heated extracts (lanes 1-3: at $85^{\circ} \mathrm{C}$ during $30,60,120 \mathrm{~s}$; lanes $4-6$ : at $90^{\circ} \mathrm{C}$ during $10,30,60 \mathrm{~s}$ ). Lane 7 contains untreated extract. Extract was applied at $20 \mu \mathrm{l}$ volume per lane. Isoenzymes $\mathrm{K} 1-\mathrm{K} 5$ have $\mathrm{pI}$ values 3-4 (acidic fraction), isoenzymes B1, B2 have pI values 8.5-9.4 (basic fraction).

(between 55 and $90^{\circ} \mathrm{C}$ ) for the times specified. The come-up time was determined by placing a fine thermocouple in the solution at the center of the tube and recording the time necessary for the solution in the tube to reach the temperature of the water bath. This time was determined to be $25 \mathrm{~s}$. After heating, the samples were cooled on ice and immediately assayed for POD activity, or frozen in liquid nitrogen and stored at $-70^{\circ} \mathrm{C}$ for further electrophoretic analysis.

\section{Isoelectrofocusing of the enzyme extract}

Soluble POD isoenzymes were separated on $7.5 \%$ polyacrylamide gel at $5^{\circ} \mathrm{C}$ in a $\mathrm{pH}$ gradient from 2 to 9 (using $5 \%$ ampholite solution) in a Multiphore II horizontal system (Pharmacia Biotech, Sweden). POD isoenzymes were stained on gel with $0.6 \mathrm{mmol} / \mathrm{l} 4$-chloro-1-naphthol and $5 \mathrm{mmol} / \mathrm{l}$ $\mathrm{H}_{2} \mathrm{O}_{2}$ in Na-acetate buffer ( $\mathrm{pH}$ 5.5) for $10 \mathrm{~min}$ at $22^{\circ} \mathrm{C}$.

\section{Preparative electrophoresis of acidic and basic enzyme fractions}

For preparative electrophoresis $1 \mathrm{ml}$ of extract was applied on $7.5 \%$ polyacrylamide gel. After separation of isoenzymes by isoelectrofocusing following the same procedure as described above, the gel parts containing either acidic or basic isoenzyme fraction were cut to small pieces, homogenized in acetate buffer ( $\mathrm{pH} 5.5$ ), shaken for $1 \mathrm{~h}$ on ice and left overnight at $6^{\circ} \mathrm{C}$, in order to elute the two fractions. Supernatant obtained after centrifugation $(3000 \times g, 2 \mathrm{~min})$, was used in the experiments of thermal inactivation and subsequent measurements of POD activity, in order to determine parameters of thermal inactivation of acidic and basic POD fractions.

By screening POD activities in heated extracts, we found that both acidic and basic fractions were inactivated more rapidly than it was the case with crude extract. Consequently, heating treatments of these two fractions were performed at lower temperatures and in a narrower range $\left(50-65^{\circ} \mathrm{C}\right.$ for basic fraction, $55-70^{\circ} \mathrm{C}$ for acidic fraction and $55-85^{\circ} \mathrm{C}$ for crude extract).

\section{Quantification of the activity of individual isoenzymes}

Quantification of the enzyme activity of individual isoenzymes was performed from zymograms, using the program Image Master TotalLab v1.11 software (Amersham Pharmacia Biotech.).

The data obtained from zymograms were expressed in pixels. Since the conversion factor from pixels to activity is not known, besides the coloration of the matching bands on the zymograms of different samples varied, we had to express activity of every individual isoenzyme as percent of its initial (control) activity. The data obtained by this procedure were used for further analysis.

\section{Inactvation model and data analysis}

Our results have shown presence of more than one POD isoenzymes in the extract (Fig. 1). In general case of existence of more than one isoenzymes in the system, each characterized by its own inactivation mechanism, overall kinetics of inactivation can be described by combining Mitscherlich and Arrhenius equations (Ponne et al. 1996; Tijskens et al. 1997):

$$
C(t, T)=\sum_{i=1}^{n} C_{\min , i}+\left(C_{0, i}-C_{\min , i}\right) e^{-k_{r e f, i} \frac{E_{i}}{R}\left(\frac{1}{T_{r e f, i}}-\frac{1}{T}\right) t}
$$

where $C(t, T)$ stands for the activity of all isoenzymes at moment $t$ and temperature $T ; C_{0, i}$ and $C_{m i n, i}$ represent initial and minimal activities of $i$ th isoenzyme; $k_{r e f, i}$ its inactivation rate; $E_{i}$ its inactivation energy and $R$ the gas constant. However, by extracting acidic and basic fractions, as well as separate isoenzymes, we can, at least approximately, reduce Eq. (1) to

$$
C(t, T)=C_{\min }+\left(C_{0}-C_{\min }\right) e^{-k_{r e f} \frac{E}{R}\left(\frac{1}{T_{r e f}}-\frac{1}{T}\right) t}
$$

since the number of isoenzymes is significantly reduced in the extracts compared to the crude extract. Therefore, for these data series non-linear regression analysis was performed on all data available, with time $t$ and temperature $T$ simultaneously as explaining variables, using Statistica 6.0 (StatSoft Inc., Tulsa, OK, USA). For each extract, parameters $C_{\text {min }}, k_{\text {ref }}$ and $E$ were estimated simultaneously. However, due to the number of experimental points, crude extract was also analyzed according to Eq. (2) instead of Eq. (1). Further, since Eq. (2) describes only those activity curves that have common $C_{\text {min }}$, it is not possible to apply one non-linear regression on the whole data set corresponding to one frac- 
tion or isoenzyme. Therefore, it was necessary to determine the number of temperature ranges and their limits, where the Eq. (2) is valid. Each separate data series, obtained at a constant temperature, was subjected to non-linear regression according to equation

$$
C(t)=C_{\min }+\left(C_{0}-C_{\min }\right) e^{-k t}
$$

Quality of fitting was expressed as $R_{\text {adj }}^{2}=1-$ [(SS residual $/(n-m)) /(\mathrm{SS}$ total $/(n-1))]$, where SS residual denotes the error sums of squares, SS total denotes total sum of squares, $n$ is number of experimental points and $m$ is number of fitted parameters.

According to grouping of values obtained for all $C_{\min }$ from these analyses, two temperature ranges, lower and higher, were determined before non-linear regression, according to Eq. (2). These ranges are: in case of crude extract $55-65^{\circ} \mathrm{C}, 70-85^{\circ} \mathrm{C}$; basic fraction $50^{\circ} \mathrm{C}, 55-65^{\circ} \mathrm{C}$; acidic fraction $55^{\circ} \mathrm{C}, 60-70^{\circ} \mathrm{C}$. For separate isoenzymes, marked as $\mathrm{K} 2, \mathrm{~K} 3$ and $\mathrm{K} 5$ on the isoelectrofocusing gel, the ranges are: $55-75^{\circ} \mathrm{C}, 85-90^{\circ} \mathrm{C}$ for $\mathrm{K} 2 ; 55-60^{\circ} \mathrm{C}, 80-90^{\circ} \mathrm{C}$ for $\mathrm{K} 3 ; 55-75^{\circ} \mathrm{C}, 85-90^{\circ} \mathrm{C}$ for $\mathrm{K} 5$. Therefore, inactivation energy could not be estimated in case of basic and acidic fractions for lower temperature range, since it comprised only one data series in both fractions.

\section{Results}

The activity of soluble POD in crude extract was 7.98 IU/g of fresh weight, while its $\mathrm{pH}$ optimum was $\mathrm{pH}$ 5.5. Two groups of isoenzymes were present in POD zymogram (Fig. 1): acidic, for which isoelectric point (pI) had values 3-4 and basic (pI 8.5-9.4). Differences in POD isoenzyme profiles brought about by temperature treatment of crude extract are also evident (Fig. 1). The effects of heating for $60 \mathrm{~s}$ at $85^{\circ} \mathrm{C}$ and $30 \mathrm{~s}$ at $90^{\circ} \mathrm{C}$ were almost the same, the basic isoenzymes disappearing completely and acidic ones decreasing in intensity. Similarly, heating for $120 \mathrm{~s}$ at $85^{\circ} \mathrm{C}$ produced the same effect as the $60 \mathrm{~s}$ treatment at $90^{\circ} \mathrm{C}$, the intensity of acidic isoenzymes further decreasing.

\section{Crude extract, acidic and basic fractions of POD isoenzymes}

The activity of POD in crude extract of $P$. omorika needles, as well as in basic and acidic fractions, after heating at different temperatures is given in Fig. 2. The estimated values of $k_{\text {ref }}, E$ and $C_{\text {min }}$ are presented in Table 1 . In addition, simulation lines obtained by using parameters of Table 1 in Eq. (2) and by setting temperature at values corresponding to the experimental points, were also shown in each panel of Fig. 2. The value of inactivation constant $k_{r e f}$ for crude extract was similar to the values of rate constants $k_{1}$ for both fractions in the lower temperature range, while in the higher temperature range $k_{r e f}$ of
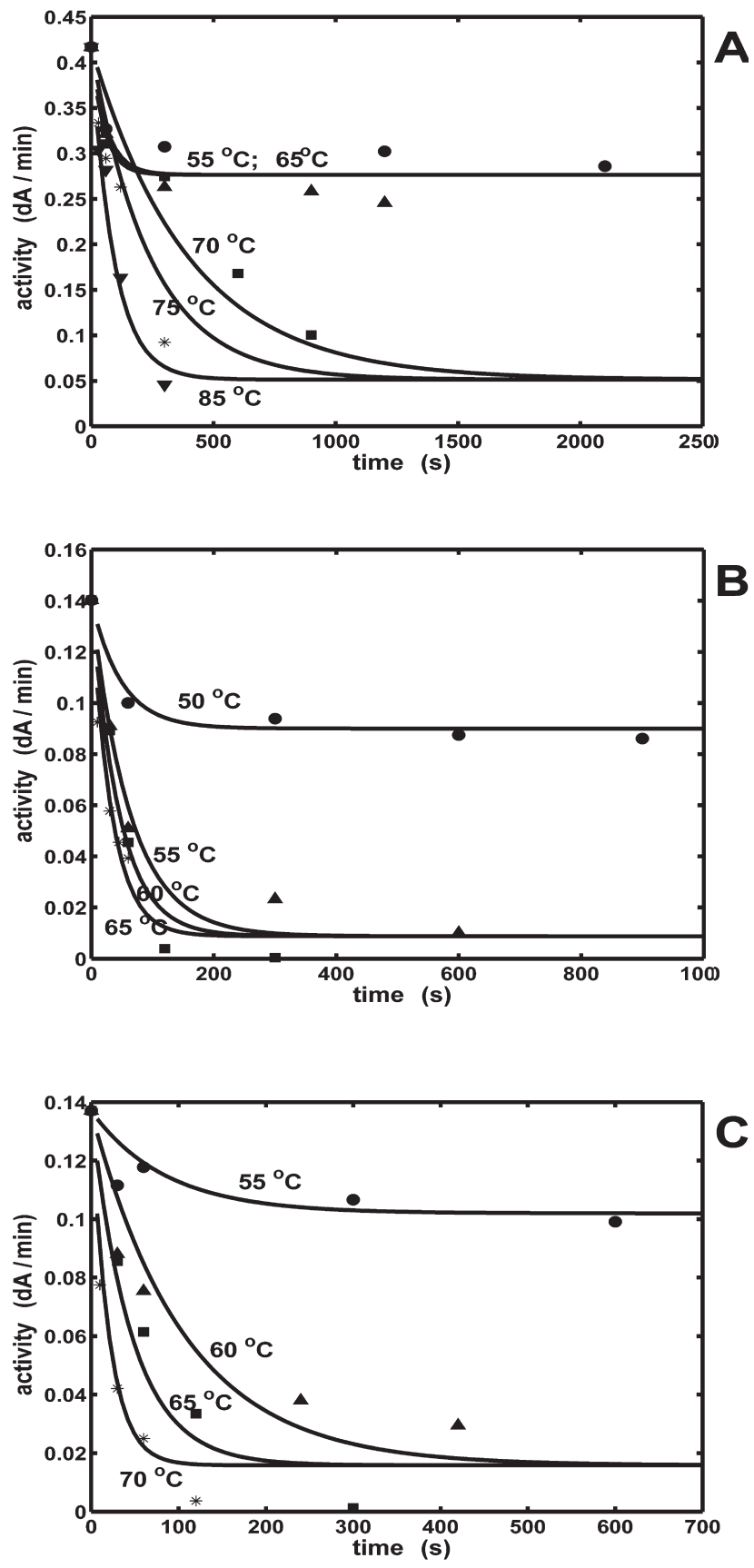

Figure 2. Activity of POD in crude extract of P. omorika needles (A), basic isoenzyme fraction (B) and acidic isoenzyme fraction $(\mathrm{C})$, as a function of time at different temperatures. Marks for experimental points: A. $55^{\circ} \mathrm{C}, \boldsymbol{\Delta} 65^{\circ} \mathrm{C}$ - $70^{\circ} \mathrm{C}, * 75^{\circ} \mathrm{C}$, $\nabla 85^{\circ} \mathrm{C}$; B. $50^{\circ} \mathrm{C}, \boldsymbol{\Delta} 55^{\circ} \mathrm{C}, 60^{\circ} \mathrm{C}, * 65^{\circ} \mathrm{C}$; C. $55^{\circ} \mathrm{C}, \boldsymbol{\Delta} 60^{\circ} \mathrm{C}$, - $65^{\circ} \mathrm{C}, * 70^{\circ} \mathrm{C}$. Simulation results are indicated with lines with (in A): $k_{1}=0.018 \mathrm{~s}^{-1}, k_{2}=0.0009 \mathrm{~s}^{-1}, E_{1}=17.0 \mathrm{~kJ} \cdot \mathrm{mol}^{-1}, E_{2}=$ $99.8 \mathrm{~kJ} \cdot \mathrm{mol}^{-1}, C_{\min 1}=0.28 \mathrm{dA} \cdot \mathrm{min}^{-1}, C_{\min 2}=0.051 \mathrm{dA} \cdot \mathrm{min}^{-1}$; (in B): $k_{1}=0.026 \mathrm{~s}^{-1}, k_{2}=0.022 \mathrm{~s}^{-1}, E_{2}=58.9 \mathrm{~kJ} \cdot \mathrm{mol}^{-1}, C_{\min 1}=$ $0.09 \mathrm{dA} \cdot \mathrm{min}^{-1}, C_{\min 2}=0.009 \mathrm{dA} \cdot \mathrm{min}^{-1}$; (in C): $k_{1}=0.013 \mathrm{~s}^{-1}, k_{2}=$ $0.0094 \mathrm{~s}^{-1}, E_{2}=156.8 \mathrm{~kJ} \cdot \mathrm{mol}^{-1}, C_{\min 1}=0.10 \mathrm{dA} \cdot \mathrm{min}^{-1}, C_{\min 2}=$ $0.016 \mathrm{dA} \cdot \mathrm{min}^{-1}$ (Table 1 ). 
crude extract was ten and twenty times lower than the values of $k_{\text {ref }}$ for the acidic and basic fraction, respectively. The obtained value of inactivation energy $\mathrm{E}$ for crude extract is between the values for acidic and basic fractions (Table 1). The initial activity $C_{0}$ of crude extract is about three times higher than corresponding values for the fractions (Fig. 2). The values of $C_{\text {min }}$ show presence of a remaining POD activity (Table 1) in case of crude extract and both fractions. Its value for crude extract is also about three to five times higher than the values for basic and acidic fractions, in both lower and higher temperature range $\left(C_{\min 1}, C_{\min 2}\right.$, respectively). In case of all three extracts (crude, basic and acidic), there is a temperature at which remaining activity decreases significantly. Namely, $C_{\min 2} / C_{\min 1}$ falls 5.5, 10 and 6.3 times for crude, basic and acidic extracts, respectively (Table 1, Fig. 2b,c). This transition, however, occurs at different temperatures: between 65 and $70^{\circ} \mathrm{C}$ for crude, between 50 and $55^{\circ} \mathrm{C}$ for basic and between 55 and $60^{\circ} \mathrm{C}$ for acidic fraction. Although basic and acidic fractions have close values of initial activity $\left(C_{0}\right)$, inactivation of acidic fraction is slower in the lower temperature range (Table 1).

\section{Individual POD isoenzymes}

By screening the zymograms of treated samples we found that the basic isoenzymes rapidly faded away during heat treatment as a consequence of thermal inactivation. For further quantitative analysis of the zymograms we therefore considered five

Table 1. Nonlinear regression results of inactivation of POD in crude extract, basic and acidic fractions from $P$. omorika needles

\begin{tabular}{|l|c|c|c|}
\hline & Crude extract & Basic fraction & Acidic fraction \\
\hline$k_{\text {ref1 }}\left(\mathrm{s}^{-1}\right) ; k_{1}$ & $0.0176(0.0056)$ & $0.0256(0.0059)$ & $0.0125(0.0039)$ \\
$k_{\text {ref } 2}\left(\mathrm{~s}^{-1}\right)$ & $0.0009(0.0003)$ & $0.0220(0.0024)$ & $0.0094(0.0020)$ \\
\hline$E_{1}\left(\mathrm{~kJ} \cdot \mathrm{mol}^{-1}\right)$ & $17.0(53.4)$ & - & - \\
$E_{2}\left(\mathrm{~kJ} \cdot \mathrm{mol}^{-1}\right)$ & $99.8(17.5)$ & $58.9(17.0)$ & $156.8(26.5)$ \\
\hline$C_{\text {min } 1}(\mathrm{dA} / \mathrm{min})$ & $0.277(0.009)$ & $0.089(0.002)$ & $0.102(0.003)$ \\
$C_{\text {min } 2}(\mathrm{dA} / \mathrm{min})$ & $0.051(0.040)$ & $0.009(0.005)$ & $0.016(0.006)$ \\
\hline$C_{0}(\mathrm{dA} / \mathrm{min})$ & 0.417 & 0.140 & 0.137 \\
\hline$T_{\text {ref1 }}\left({ }^{\circ} \mathrm{C}\right)$ & 60 & - & - \\
$T_{\text {ref2 } 2}\left({ }^{\circ} \mathrm{C}\right)$ & 60 & 60 & 60 \\
\hline$T_{\text {range1 }}\left({ }^{\circ} \mathrm{C}\right)$ & $55-65$ & 50 & 55 \\
$T_{\text {range2 }}\left({ }^{\circ} \mathrm{C}\right)$ & $70-85$ & $55-65$ & $60-70$ \\
\hline$N_{\text {obs1 }}$ & 10 & 5 & 4 \\
$N_{\text {obs2 }}$ & 15 & 15 & 15 \\
\hline$R_{1}^{2}$ adj $(\%)$ & 85.7 & 96.3 & 91.3 \\
$R_{2}^{2}$ adj $(\%)$ & 89.4 & 96.1 & 93.6 \\
\hline
\end{tabular}

$k$, inactivation rate, valid for basic and acidic fraction in the lower temperature range; $k_{\text {ref }}$ inactivation constant; $E$, inactivation energy; $C_{\text {min }}$, minimal POD activity; $C_{0}$, initial activity; $T_{r e f}$, reference temperature; $T_{\text {range }}$, temperature range; $N_{o b s}$, number of observations. Indexes 1,2 denote lower and upper temperature range, respectively. Statistically significant estimated values of parameters are shaded. acidic isoenzymes (K1-K5), which were present throughout the experiment. Table 2 contains parameters obtained as results of non-linear regression analysis $\left(k_{r e f}, E\right.$ and $\left.C_{\text {min }}\right)$ of thermal inactivation for three isoenzymes (K2, K3 and K5) which differ in kinetic properties after heating at high temperatures (Fig. 1). Their relative activities (expressed as percentage of initial activities) after heating at different temperatures are presented in Fig. 3, as well as corresponding simulation lines. The inactivation rate $k_{\text {ref }}$ in the lower temperature range is 1.5 times higher for $\mathrm{K} 3$ isoenzyme than in case of K2 and 2.7 times higher than for $\mathrm{K} 5$. In the higher temperature range, the value of $k_{r e f}$ for isoenzyme K2 is considerably lower than the corresponding values for $\mathrm{K} 3$ and $\mathrm{K} 5$ (Table 2). The inactivation energy for $\mathrm{K} 3$ isoenzyme in the lower temperature range $\left(E_{1}\right)$ is higher $\left(298.1 \mathrm{~kJ} \mathrm{~mol}^{-1}\right)$ in comparison with the two other isoenzymes. In the higher temperature range, the inactivation energy $\left(E_{2}\right)$ of isoenzyme K2 is 2.4 times higher than for K3 and even 13 times higher than for K5. In the lower temperature range, the remaining activity has similar values for all three isoenzymes. In the higher temperature range, however, the isoenzyme $\mathrm{K} 3$ retains a significant non-zero level of remaining activity, while the activity of $\mathrm{K} 2$ and $\mathrm{K} 5$ falls approximately to zero, in respect to their initial activities.

\section{Discussion}

Maximal POD activity versus $\mathrm{pH}$ change was similar to that reported for Picea abies (Polle et al. 1990). The apoplast $\mathrm{pH}$

Table 2. Nonlinear regression results of inactivation of separated POD isoenzymes K2, K3 and K5 from P. omorika needles

\begin{tabular}{|l|c|c|c|}
\hline & $\mathrm{K} 2$ & $\mathrm{~K} 3$ & $\mathrm{~K} 5$ \\
\hline$k_{\text {ref1 }}\left(\mathrm{s}^{-1}\right)$ & $0.0028(0.0005)$ & $0.0043(0.0008)$ & $0.0016(0.0003)$ \\
$k_{\text {ref2 }}\left(\mathrm{s}^{-1}\right)$ & $2.7468 \times 10^{-8}(0)$ & $0.0001(0.0001)$ & $0.0066(0.0077)$ \\
\hline$E_{1}\left(\mathrm{~kJ} \cdot \mathrm{mol}^{-1}\right)$ & $132.8(11.7)$ & $298.1(29.2)$ & $146.9(12.2)$ \\
$E_{2}\left(\mathrm{~kJ} \cdot \mathrm{mol}^{-1}\right)$ & $521.1(48.1)$ & $220.4(49.7)$ & $39.2(40.5)$ \\
\hline$C_{\text {min } 1}(\%)$ & $54.36(3.60)$ & $48.80(2.59)$ & $56.37(3.56)$ \\
$C_{\text {min2 }}(\%)$ & $6.28(3.10)$ & $28.52(4.96)$ & $0.00(8.43)$ \\
\hline$C_{0}(\%)$ & 100 & 100 & 100 \\
\hline$T_{\text {ref1 }, 2}\left({ }^{\circ} \mathrm{C}\right)$ & 60 & 60 & 60 \\
\hline$T_{\text {range1 }}\left({ }^{\circ} \mathrm{C}\right)$ & $55-75$ & $55-60$ & $55-75$ \\
$T_{\text {range2 }}\left({ }^{\circ} \mathrm{C}\right)$ & $85-90$ & $80-90$ & $85-90$ \\
\hline$N_{\text {obs1 }}$ & 15 & 9 & 20 \\
$N_{\text {obs2 }}$ & 10 & 14 & 10 \\
\hline$R_{1}^{2}$ adj $(\%)$ & 91.5 & 98.3 & 89.5 \\
$\mathrm{R}_{2}^{2}{ }_{\text {adj }}(\%)$ & 97.2 & 85.2 & 95.4 \\
\hline
\end{tabular}

$k_{\text {ref }}$, inactivation constant; $E$, inactivation energy; $C_{\text {min }}$, minimal POD activity; $C_{0}$, initial activity; $T_{\text {ref }}$, reference temperature; $T_{\text {range }}$, temperature range; $N_{o b s}$, number of observations. Indexes 1, 2 denote upper and lower temperature range, respectively. Statistically significant estimated values of parameters are shaded. 
in conifer needles was shown to be around 5.5 (Pfanz and Dietz 1987; Graber et al. 2003), which means that PODs attain their highest activity at physiological $\mathrm{pH}$ value. The same $\mathrm{pH}$ value is also in common use for guaiacol assay of POD activity (Chance and Maehly 1955).

The POD zymogram change induced by heat treatment (Fig. 1) shows that basic isoenzymes were completely inactivated after short heating times at high temperatures (85 and $90^{\circ} \mathrm{C}$ ), while acidic ones were more resistant. This could mean that basic isoenzymes are more labile towards high temperature than acidic ones.

The high $R^{2}$ adj values obtained for crude extract, as well as acidic and basic fractions, show that applied model accounts for $>91 \%$ of variance of POD temperature inactivation data in two fractions and $>85 \%$ in crude extract. Higher values of $R_{\text {adj }}^{2}$, obtained for the fractions in comparison with the crude extract, indicate that the model described in Eq. (2) is more appropriate for the inactivation process of the fractions than for the crude extract. The crude extract should be considered as a more complex system, where more fractions are present. The lower value of $k_{r e f 2}$ for POD in the crude extract in comparison with the fractions, may be in accordance with this higher complexity of the crude extract. The fact that decrease in the remaining activity occurs at the higher temperature for the crude extract, in comparison with acidic and basic fractions, may also be attributed to the fact that crude extract is a more complex system than the two separate fractions. The obtained value of inactivation energy for crude extract, which is neither closer to the acidic nor to the basic isoenzyme fraction, may be an indication that both fractions have approximately even contribution to the inactivation energy of the total POD isoenzyme pool in the crude extract. It is worth noting that the values obtained for inactivation energy are apparent, as the crude extract, as well as fractions, contain isoenzymes of different temperature stability (Fig. 1). The value of $E_{2}$ for crude extract $\left(99.8 \mathrm{~kJ} \cdot \mathrm{mol}^{-1}\right.$, Table 1$)$ is intermediate considering values found for class III PODs from some other plant species, such as pumpkin $\left(86.2 \mathrm{~kJ} \cdot \mathrm{mol}^{-1}\right.$ (Gonçalves et al. 2007)), carrot and potato (480 and $478 \mathrm{~kJ} \cdot \mathrm{mol}^{-1}$, respectively (Anthon and Barrett 2002)), and tomato (657 kJ.mol ${ }^{-1}$ (Anthon et al. 2002)). Data on POD thermal inactivation are scarce for tree species, especially for conifers. Thermal inactivation is generally a consequence of increased total kinetic energy of the molecule that leads to weakening of intramolecular interactions, ultimately destroying the ternary structure. It had been shown previously that intramolecular hydrofobic interactions have an important role in thermal stability (Daniel et al. 1996), as well as oligosaccharide component in case of class III PODs (Van Huystee et al. 2004). Besides, it was shown that the loosening of $\mathrm{Ca}^{2+}$ ions causes up to $40 \%$ decrease in the activity of horseradish POD (Veitch 2004).

The temperature range for thermal inactivation of both isoenzyme fractions was relatively narrow compared to crude
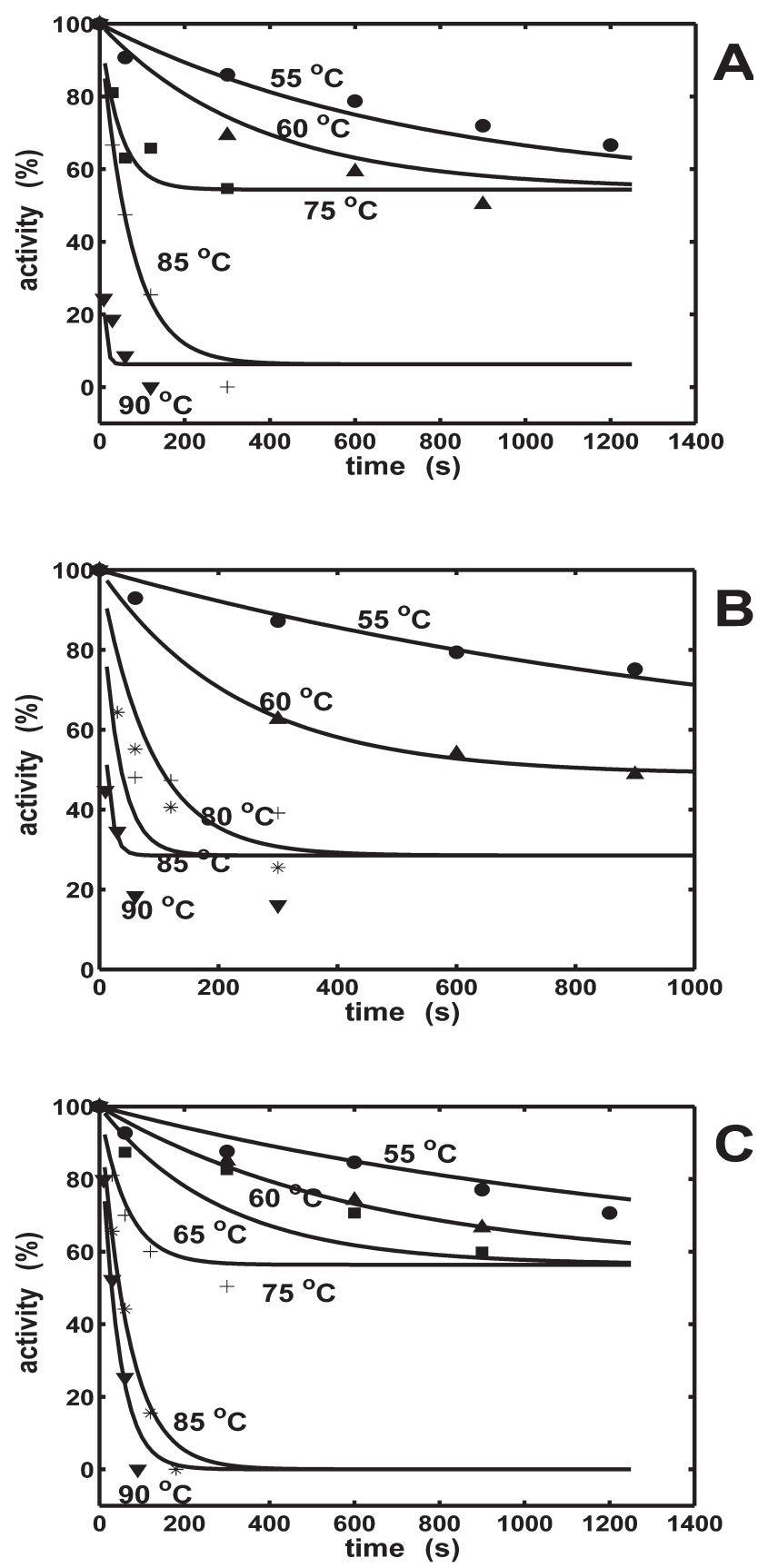

Figure 3. Activity of individual POD isoenzymes K2 (A), K3 (B) and K5 (C), from P. omorika needle extract, as a function of time at different temperatures. Marks for experimental points: A. $55^{\circ} \mathrm{C}, \boldsymbol{\Delta} 60^{\circ} \mathrm{C}, 75^{\circ} \mathrm{C},+85^{\circ} \mathrm{C}, \nabla 90^{\circ} \mathrm{C}$; B. $55^{\circ} \mathrm{C}, \boldsymbol{\Delta} 60^{\circ} \mathrm{C}$, $+80^{\circ} \mathrm{C}, * 85^{\circ} \mathrm{C}, \nabla 90^{\circ} \mathrm{C}$; C. $55^{\circ} \mathrm{C}, \boldsymbol{\Delta} 60^{\circ} \mathrm{C}$, $65^{\circ} \mathrm{C},+75^{\circ} \mathrm{C}$, $* 85^{\circ} \mathrm{C}, \boldsymbol{\nabla} 90^{\circ} \mathrm{C}$. Simulation results are indicated with lines with (in A): $k_{1}=0.0028 \mathrm{~s}^{-1}, k_{2}=2.75 \times 10^{-8} \mathrm{~s}^{-1}, E_{1}=132.8 \mathrm{~kJ} \cdot \mathrm{mol}^{-1}$, $E_{2}=521.1 \mathrm{~kJ} \cdot \mathrm{mol}^{-1}, C_{\min 1}=54.36 \%, C_{\min 2}=6.28 \%$; (in B): $k_{1}=0.0043 \mathrm{~s}^{-1}, k_{2}=0.0001 \mathrm{~s}^{-1}, E_{1}=298.1 \mathrm{~kJ} \cdot \mathrm{mol}^{-1}, E_{2}=220.4$ $\mathrm{kJ} \cdot \mathrm{mol}^{-1}, C_{\min 1}=48.80 \%, C_{\min 2}=28.52 \%$; (in C): $k_{1}=0.0016 \mathrm{~s}^{-1}$, $k_{2}=0.0066 \mathrm{~s}^{-1}, E_{1}=146.9 \mathrm{~kJ} \cdot \mathrm{mol}^{-1}, E_{2}=39.2 \mathrm{~kJ} \cdot \mathrm{mol}^{-1}, C_{\min 1}=$ $56.37 \%, C_{\min 2}=0.00 \%$ (Table 2). 
extract, which was probably due to the isolation procedure applied. Elution of the fractions from gel after electrophoretic separation caused a considerable dilution that could destabilize the enzyme.

As it is very difficult to separate and purify sufficient quantities of individual isoenzymes, we employed a method of quantification of enzyme activity directly from zymograms in order to determine thermal inactivation of heated samples (Ludikhuyze et al. 1998). This study showed that the applied method can also be used as a rapid and practical procedure for screening electrophoretically separated isoenzymes for their thermostability. This may be a basis for separation of thermally most resistant isoenzymes from a bulk of different isoenzymes. Such approach could be used in experiments where $P$. omorika would be grown in controlled conditions and a correlation between applied temperature and expression of particular isoenzymes would be analysed. This could lead to the conclusion which isoenzyme(s) is most responsible for thermal resistance of this species.

As the apparent energy of inactivation reflects the average energy of inactivation of all isoenzymes present in an extract, the isoenzyme with the highest activity has the strongest influence. The contribution of individual basic isoenzymes in thermally inactivated crude extract was low, as evident from their rapid disappearance from zymogram (Fig. 1). They were therefore not considered in further study of individual isoenzymes. Quantification data on the enzyme activity of acidic isoenzymes from zymograms, were used for analysis of inactivation kinetics. The high $R_{\text {adj }}^{2}$ values obtained for all three analysed isoenzymes, show that applied model accounts for $>89 \%$ of variance of POD temperature inactivation data in the lower temperature range and $>85 \%$ in the higher range. Although the isoenzyme $\mathrm{K} 2$ is characterized with the lowest value of inactivation constant $k_{r e f 2}$ and the highest inactivation energy $E_{2}$, the isoenzyme $\mathrm{K} 3$, having significantly higher $C_{\min 2}$ than the other two, is most prominent after $120 \mathrm{~s}$ heating at $85^{\circ} \mathrm{C}$ (Fig. 1). It is interesting to note that, although in the lower temperature range the three isoenzymes have similar $C_{\min 1}$, additional heating induces almost complete diminution of $C_{\min 2}$ in case of $\mathrm{K} 2$ and $\mathrm{K} 5$. The presence of remaining activity for $\mathrm{K} 3$ in the higher temperature range additionally shows its heating resistance. These data may also be an indication of the highest contribution of $\mathrm{K} 3$ isoenzyme, in comparison with $\mathrm{K} 2$ and $\mathrm{K} 5$, to the high remaining activity of the crude extract (Table 1).

There is a gradual decline in the activity (Gómez-Casati et al. 2000) due to complex and not fully explained processes of thermal denaturation (Lu and Whitaker 1974; Tamura and Morita 1975; Chen et al. 2008). Most of the calculated values of inactivation energy are intermediate in comparison with a range of values found by other authors for class III POD isoenzymes from different species, such as turnip (three isoenzymes $-113,130$ and $172 \mathrm{~kJ} \cdot \mathrm{mol}^{-1}$ (Duarte-Vazquez et al. 2000)), cauliflower (89 kJ.mol ${ }^{-1}$ (Lee and Pennesi 1984)), asparagus (140 kJ.mol ${ }^{-1}$ (Ganthavorn et al. 1991)), brussels sprouts (172 kJ·mol ${ }^{-1}$ (Regalado et al. 1999)), soybean (76.9 $\mathrm{kJ} \cdot \mathrm{mol}^{-1}$ (McEldoon and Dordick 1996)).

In summary, in a bulk of class III POD isoenzymes from P. omorika needles there are two isoenzyme fractions that we isolated from the gel after their electrophoretic separation, acidic and basic, of which the former is more thermostable than the latter. We also found that there are differences among acidic isoenzymes regarding their thermostability, which may imply their different contribution to the thermostability of the whole extract. All of the obtained values of inactivation energy are intermediate compared to the values reported by other authors for various plant species. The applied procedure of enzyme activity quantification directly from gel, was shown to be very useful in cases when there are many isoenzymes in an extract with close $\mathrm{pI}$ values that are difficult to separate in sufficient quantities using any of the currently available chromatographic methods.

Acknowledgement. Grant No. 143043 of the Ministry of Science and Technology of the Republic of Serbia supported this study.

\section{References}

Aiman F., Qayyum H. (2007): A role of glycosyl moieties in the stabilization of bitter gourd (Momordica charantia) peroxidase. Int. J. Biol. Macromol. 41, 56-63

Anthon G. E., Barrett D. M. (2002): Kinetic parameters for the thermal inactivation of quality-related enzymes in carrots and potatoes. J. Agric. Food Chem. 50, 4119-4125

Anthon G. E., Sekine Y., Watanabe N., Barrett D. M. (2002): Thermal inactivation of pectin methyl esterase, polygalacturonase, and peroxidase in tomato juice. J. Agric. Food Chem. 50, 6153-6159

Bazzaz F. A. (1996): Plants in changing environments: Linking physiological, population and community ecology. Cambridge University Press

Bogdanović J., Dučić T., Milosavić N., Vujčić Z., Šijačić M., Isajev V., Radotić K. (2005): Antioxidant enzymes in the needles of different omorika lines. Arch. Biol. Sci. 57, 277-282

Bogdanović J., Djikanović D., Maksimović V., Tufegdžić S., Djoković D., Isajev V., Radotić K. (2006): Phenolics, lignin content and peroxidase activity in Picea omorika lines. Biol. Plant. 50, 461-464

Bogdanović J., Milosavić N. B., Prodanović R. M., Dučić T., Radotić K. (2007): Variability of antioxidant enzyme activity and isoenzyme profile in needles of Serbian spruce (Picea omorika (Pančić) Purkynĕ), Biochem. Syst. Ecol. 35, 263-273

Castillo F. J. (1986): Extracellular peroxidases as markers of stress? In: Molecular and Physiological Aspects of Plant Peroxidases. (Eds. H. Grepin, C. Penel and T. Gaspar), pp. 419-426, University of Geneva

Chance B., Maehly A. C. (1955): Assay of catalases and peroxidases. In: Methods in Enzymology. (Eds. S. P. Colowick and N. O. Kaplan), Vol. 2, pp. 765-775, Academic Press Publishers, New York 
Chen Y., Ding F., Nie H., Serohijos A. W., Sharma S., Wilcox K. C., Yin S., Dokholyan N. V. (2008): Protein folding: then and now. Arch. Biochem. Biophys. 469, 4-19

Čolić D. B. (1957): Some pioneer characters in the Serbian spruce (Picea omorika Pančić) and its role in the succession of plant communities. Arch. Biol. Nauka (Belgrade) 9, 51-60

Čolić D. (1966): Fire as an ecological factor in the succession of Pančić's omorika communities and in the reduction of its area. Conservation Nature, Belgrade 33, 1-167

Daniel R. M., Dines M., Petach H. (1996): The denaturation and degradation of stable enzymes at high temperatures. Biochem. J. 317, 1-17

Duarte-Vazquez M. A., Garcia-Almendarez B., Regalado C., Whitaker J. R. (2000): Purification and partial characterization of three turnip (Brassica napus L.) peroxidases. J. Agric. Food Chem. 48, 1574-1579

Ganthavorn C., Nagal C., Powers J. R. (1991): Thermal inactivation of asparagus lipoxygenase and peroxidase. J. Food Sci. 56, 47-49

Gilman E. F., Watson D. G. (1994): Picea omorika. Serbian Spruce. Fact Sheet ST-451, Florida Cooperative Extension Service, University of Florida, USA

Gómez-Casati D. F., Preiss J., Iglesias A. A. (2000): Studies on the effect of temperature on the activity and stability of cyanobacterial ADP-glucose phosphorylase. Arch. Biochem. Biophys. 384, 319-326

Gonçalves E. M., Pinheiro J., Abreu M., Brandão T. R. S., Silva C. L. M. (2007): Modelling the kinetics of peroxidase inactivation, colour and texture changes of pumpkin (Cucurbita maxima L.) during blanching. J. Food Eng. 81, 693-701

Graber J. H., Hatfield R. D., Ralph J. (2003): Apoplastic pH and monolignol addition rate effects on lignin formation and cell wall degradability in maize. J. Agric. Food Chem. 51, 4984-4989

Hendrickx M., Ludikhuyze L., Van den Broeck I., Weemaes C. (1998): Effects of high pressure on enzymes related to food quality. Trends Food Sci. Technol. 9, 197-203

Jovanović B. (1970): Gymnospermae. In: Flore de la Republique Socialiste de Serbie. I. (Ed. M. Josifović), pp. 135-137, Academie Serbe des Sciences et des Arts, Beograd

Kawano T. (2003): Roles of reactive oxygen species-generatig peroxidase reactions in plant defense and growth induction. Plant Cell Rep. 21, 829-837

Král D. (2002): Assessing the growth of Picea omorika (Pančić) Purkyně in the Masaryk forest training forest enterprise at Krrtiny. J. Forest Sci. 48, 388-398

Lee C. Y., Pennesi A. P. (1984): Isolation and further characterization of a heat resistant peroxidase isozyme from cauliflower. J. Food Sci. 49, 1616-1617

Lu A. T., Whitaker J. R. (1974): Some factors affecting rates of heat inactivation and reactivation of horseradish peroxidase. J. Food Sci. 39, 1173-1178

Ludikhuyze L. R., Van den Broeck I., Weemaes C. A., Hendrickx M. E. (1998): High pressure and thermal denaturation kinetics of soybean lipoxygenase: a study based on gel electrophoresis. Lebensm. Wiss. Technol. 31, 680-686

McEldoon J. P., Dordick J. S. (1996): Unusual thermal stability of soybean peroxidase. Biotechnol. Prog. 12, 555-558
Morales-Blancas E. F., Chandia V. E., Cisneros-Zevallos L. (2002): Thermal inactivation kinetics of peroxidase and lipoxygenase from broccoli, green asparagus and carrots. J. Food Sci. 67, 146-154

Pfanz H., Dietz K. J. (1987): A fluorescence method for the determination of the apoplastic proton concentration in intact leaf tissues. J. Plant Physiol. 129, 41-48

Polle A., Chakrabarti K., Schürmann W., Rennenberg H. (1990): Composition and properties of hydrogen peroxide decomposing systems in extracellular and total extracts from needles of Norway spruce (Picea abies L., Karst.). Plant Physiol. 94, 312-319

Ponne C. T., Möller A. C., Tijskens L. M. M., Bartels P. V., Meijer M. M. T. (1996): Influence of microwave and steam heating on lipase activity and microstructure of rapeseed (Brassica napus). J. Agric. Food Chem. 44, 2818-2824

Regalado C., Pérez-Arvizu O., García-Almendarez B. E., Whitaker J. R. (1999): Purification and properties of two acidic peroxidases from Brussels sprouts (Brassica oleraceae L.). J. Food Biochem. 23, 435-450

Rodrigo C., Rodrigo M., Alvarruiz A., Frígola A. (1996): Thermal inactivation at high temperatures and regeneration of green asparagus peroxidase. J. Food Prot. 59, 1065-1071

Ros Barceló A. (2000): Peroxidase and $\mathrm{H}_{2} \mathrm{O}_{2}$ production by plant cells: truths and clues. Curr. Top. Phytochem. 3, 197-202

Schweiggert U., Schieber A., Carle R. (2006): Effects of blanching and storage on capsaicinoid stability and peroxidase activity of hot chili peppers (Capsicum frutescens L.). Innovative Food Sci. Emerging Technol. 7, 217-224

Takahama U. (2004): Oxidation of vacuolar and apoplastic phenolic substrates by peroxidase: Physiological significance of oxidation reactions. Phytochem. Rev. 3, 207-219

Tamura Y., Morita Y. (1975): Thermal denaturation and regeneration of Japanese-radish peroxidase. J. Biochem. 78, 561-571

Tijskens L. M. M., Rodis P. S., Hertog M. L. A., Waldroin K. W., Ingham L., Proxenia N., van Dijk C. (1997): Activity of peroxidase during blanching of peaches, carrots and potatoes. J. Food Eng. 34, 355-370

Tucić B., Stojković B. (2001): Shade avoidance syndrome in Picea omorika seedlings: a growth-room experiment. J. Evol. Biol. 14, 444-455

Van Huystee R. B. (1987): Some molecular aspects of plant peroxidase biosynthetic studies. Ann. Rev. Plant Physiol. 38, 205-219

Van Huystee R. B., Roig M. G., Shynrov V., Sakharov I. (2004): Peroxidase stability related to its calcium and glycans. Phytochem. Rev. 3, 19-28

Vasquez-Caicedo A. L., Schilling S., Carle R., Neidhart S. (2007): Effects of thermal processing and fruit matrix on $\beta$-carotene stability and enzyme inactivation during transformation of mangoes into purée and nectar. Food Chem. 102, $1172-1186$

Veitch N. C. (2004): Structural determinanats of plant peroxidase function. Phytochem. Rev. 3, 3-18

Received: July 7, 2008

Final version accepted: December 18, 2008 